\title{
EXPLANATORY AND PREDICTIVE MODEL OF THE ADOPTION OF P2P PAYMENT SYSTEMS
}

\author{
Lara-Rubio, J.; Villarejo-Ramos, A.F.; Liébana-Cabanillas, F.
}

\begin{abstract}
The purpose of this paper is to identify the factors affecting to the intention to use of peer-to-peer (P2P) mobile payment. Although mobile technology has become part of everyday life, certain actions and services, such as mobile payments, are still used relatively infrequently. In this paper, we analyse consumers' adoption of P2P mobile payment services. Following a review of previous literature in this field, we identify the main factors that determine the adoption of mobile payments, and then perform a logistic regression (LR) analysis and propose a neural network to predict this adoption. From the logistic regression results obtained we conclude that six variables significantly influence intentions to use P2P payment: ease of use, perceived risk, personal innovativeness, perceived usefulness, subjective norms and perceived enjoyment. With respect to the nonparametric technique, we find that the multilayer perceptrons (MLP) prediction model for the use of $\mathrm{P} 2 \mathrm{P}$ payment obtains higher AUC values, and thus is more accurate, than the LR model. This paper is a pioneer study of intention to use with mobile payment using these methodologies. The outcome of this research has important implications for the theory and practice of the adoption of P2P mobile payment services.
\end{abstract}

Key words: Mobile payment; Adoption; P2P; Intention to use; Neural networks 


\section{INTRODUCTION}

Since the late 1990s, commercial transactions have experienced a rapid digital transformation, driven by consumers' access to new technologies (Mossberger, 2007) and by corporations' efforts to become more customer-centric (Berman, 2012). Digital innovations have changed corporations' strategies (Kane et al., 2015), business to consumer exchanges (Xu, 2014), consumption patterns (Wilska, 2003) and interactions among consumers (Kim et al., 2019).

Financial services have been at the forefront of this digital revolution (McMillan, 2015), leveraging and implementing innovations such as mobile banking, peer-to-peer (P2P) (Ma et al., 2018), lending behavior (Cai et al., 2016), payments and blockchain (Dapp et al., 2015), with the USA and Africa (Shaikh \& Karjaluoto, 2015) at the forefront of this activity, driven by a dense financial-technology (fintech) entrepreneurial ecosystem (Haddad \& Hornuf, 2016) and by the inadequacy of incumbent financial institutions, respectively.

The speed with which technology is adopted varies according to the perceived need for the service (Liébana-Cabanillas et al., 2014 a,b; Kujala et al., 2017), the ability to leverage consumers' readiness for change, the influence of third parties (Liébana-Cabanillas et al., 2014 c) and support from large corporations (UPGlobal, 2013). The case of P2P payments is a clear example of a technology that has encountered resistance in all these dimensions.

Many companies tried and failed to launch digital P2P systems (e.g., CyberCash) before 1999, when PayPal offered the first successful electronic payment system independent of traditional financial services firms (PMNTS.com, 2015). In 1998, X.com, its mother company together with Confinity, identified customers' need for an electronic money transfer system (Lillington, 1999; Cohan, 2013), but it was not until consumers perceived the need for a secure payment platform for online purchases (Richtel, 2002), and when eBay signed a strategic partnership that ultimately became a corporate acquisition, that PayPal became a mass service for online payments (eBay, 2002).

Since then, many other non-traditional financial services have appeared, including Square Cash, clearXchange, Google and Apple Wallet. Others, like Venmo or Snapcash, embed cash transfers within social media experiences. All these new players address new consumer needs, leverage increased consumer readiness and obtain support from large corporations.

Traditional financial services firms have started to perceive the P2P payment platform as a threat, because as it facilitates money flows out of their networks (Denecker et al., 2014). In response, banks have banded together to create common platforms as alternatives to new fintech models, leveraging their existing infrastructure and market access (Denecker et al., 2014).

Most financial services firms have already started digital transformations, implementing lessons learned from early adopters, and entering into partnerships with tech startups to include additional applications in their corporate solutions.

Bizum is an example of a traditional financial player's response to P2P platforms in Spain. With over 500,000 unique users (Bizum, 2017a), and built from the alliance of 27 banks (Bizum, 2017a), it has achieved a volume of 50M euro in transactions in less than a year of existence (Blanco, 2017; Bizum, 2017b). The P2P payments market is expected 
to grow to $\$ 2.3 \mathrm{~T}$ by 2019 , with Latin America and Europe, the Middle East and Africa (EMEA) leading this surge with 9\% and 7\% compound annual growth, respectively, between 2014 and 2019 (Bansal et al., 2015). In recent years other apps such as Yaap or Verse entered the competition but failed to replicate the success of Bizum.

Nevertheless, much remains to be done before this technology is fully extended among traditional financial services providers and their customers. Technology adoption will differ substantially among different consumer segments, and therefore will require different strategies to be applied. The novel aspect of the research we present lies in the field of analysis addressed; to our knowledge, no previous empirical study has been undertaken regarding the adoption of systems enabling person-to-person mobile payment (P2PM-pay), based on mobile cash. We believe the focus of this study is timely and necessary. Moreover, two factors of great importance are considered: firstly, although some studies have been conducted to analyse the importance of mobile payment systems (Liébana-Cabanillas et al., 2016; Ramos de Luna et al., 2019; Singh et al., 2020), we examine in particular how these new P2P payment systems function in Spain, through explanatory variables approached in similar research studies. Secondly, the methodology we employ, based on logistic regression analysis and the creation of a neural network, will enable us to identify the factors that encourage or inhibit the use of P2PM-pay systems. From the results obtained, their implications and the conclusions drawn, we then propose measures for overcoming some of these barriers to adoption and suggest interesting areas for future research.

The conclusions obtained from the present study provide useful new knowledge for banks, commercial managers, clients, system analysts, citizens at large, and other actors and stakeholders.

\section{PEER-TO-PEER MOBILE PAYMENT SYSTEM: BIZUM}

Person-to-person payments (P2P) is an online technology that allows customers to transfer funds from their bank account or credit card to another individual's account via the internet or a mobile phone. According to the annual barometer of new forms of payment, published by MasterCard, 10.4\% of digital customers (Spanish citizens aged 2455 years who have made online purchases or contactless payments in a physical store during the last six months) use their mobile phone to make payments in physical stores, via NFC technology. Another means of payment that is becoming increasingly popular is $\mathrm{P} 2 \mathrm{P}$ payments, which are known to $48.8 \%$ and used by $9 \%$ of respondents. According to a recent report by Javelin (2015), the number of mobile P2P users will soon grow rapidly, from 69 million in 2015 to 126 million by 2020. By 2019, it is expected that over half of all mobile device owners will be using mobile P2P. In this respect, the Mercator Advisory Group (2015) reported that "more than 50 mobile personto-person (P2P) payment services have been launched in recent years to capitalize on this changing consumer preference. These systems or services generally have certain characteristics in common, including enabling payments to individuals or businesses, requiring a smartphone, and having a daily transfer limit. Some services in Europe allow customers to opt to make online payments via their mobile device, but most do not enable payment at the physical point of sale (POS) or cash withdrawals at an automated teller machine, and they tend to be limited to one market or select geographies". 
In Spain, after years of battling each other, the banks have decided to join forces to address the mobile payment competition they face on various fronts: from mobile phone manufacturers (Samsung Pay and Apple Pay), telecom operators (Vodafone Wallet) and the internet giants (Android Pay). Thus, some thirty Spanish banks representing 95\% of the financial market have come together to create Bizum, a technological platform that integrates mobile payment applications among all the entities involved, to enable transfers between individuals (free of charge in the launch phase) and, soon, payments in physical shops and online purchases.

The way Bizum operates is very simple. After users download the banking app, they link their bank account to the number associated with their mobile phone subscription. Once this process has been completed, they choose a contact or input the mobile number of the person they are making the transaction with. Once the user enters the transaction amount, he or she will receive a short text message (SMS) with a code that must be entered in the Bizum app in order to complete the operation, and then the funds are immediately transferred between the two accounts. Recipients also receive a text message when the transferred funds are available in their accounts.

Immediacy is a key feature and one of the main advantages of using Bizum, as funds are instantly available, whereas online transactions can take several days if different banking companies are involved. In the case of Bizum, senders and recipients just need to download their respective banking apps in order to operate through Bizum.

Bizum allows users to check who else is using this service through the mobile device's Contacts app. When Bizum users try to interact with contacts who have not installed the app, these contacts will receive an SMS with a link to download the Bizum app. As soon as they receive the link, they have 7 days to complete the transaction in order to successfully collect the payment. In the case of Bizum, it is important to note that the personal transaction sender is unable to see the account number of the recipient and vice versa; only mobile phone numbers are shared.

\section{METHODOLOGICAL APPROACH}

\subsection{Study fieldwork and information collection.}

The aim of this empirical study is to examine the adoption of P2P mobile payment systems. To do so, we performed a sequential quantitative analysis, in three phases.

In the first phase, an initial review was conducted of the mobile payment methods currently employed in the markets, taking as our source material the main databases of scientific publications. With the preliminary results and after setting up and working with two focus groups, one with payment officers from five Spanish financial institutions and the other with ten users of payment systems, a set of questions was defined to be evaluated by the participants. This first phase took place in the first half of October 2016.

In the second phase, a qualitative study was conducted with 25 users to verify the degree of reliability of the questions considered previously. This phase was carried out in the second half of October 2016, and the following concepts and variables were found to be most relevant: perceived ease of use, perceived risk, personal innovativeness, subjective norms, perceived enjoyment and intention of use. The full list of questions included is shown in Annex 1. 
Finally, after the appropriate verifications, an online questionnaire was drawn up, based on the above questions, and presented to a panel of mobile service users. The questionnaire was divided into three thematic blocks: control questions, research questions and socio-demographic data. A study was then conducted via the teaching support platform, managed by the authors, to assess the value of the questionnaire, to identify necessary modifications and to determine the acceptance level, dimensionality, reliability and validity of the proposed scales. Once all the modifications detected in these initial phases had been implemented, the questionnaire was judged ready for the final study. The survey was then conducted in January 2017, with a sample of 701 participants (Table 1).

The questionnaire was originally drafted in English, but it was intended for smartphone users to use in Spanish. Therefore, the English questionnaire was translated into Spanish by a professional native English translator and by the researchers, working independently. After a careful analysis of the differences between these independently translated questionnaires, a definitive version of the Spanish questionnaire was obtained. This final version was then translated back into English by another professional native English translator to ensure consistency between the English and Spanish versions of the questionnaire (Brislin, 1970). The characteristics of the sample population are shown in Table 1.

Table 1. Participant characteristics

\begin{tabular}{|c|c|c|c|}
\hline & & Frequency & Percentage \\
\hline \multirow[t]{2}{*}{ Sex } & Male & 324 & $46.22 \%$ \\
\hline & Female & 377 & $53.78 \%$ \\
\hline \multirow[t]{6}{*}{ Age } & $18-24$ & 297 & $42.37 \%$ \\
\hline & $25-34$ & 227 & $32.38 \%$ \\
\hline & $35-44$ & 132 & $18.83 \%$ \\
\hline & $45-54$ & 34 & $4.85 \%$ \\
\hline & $55-64$ & 10 & $1.43 \%$ \\
\hline & 65 and over & 1 & $0.14 \%$ \\
\hline \multirow[t]{5}{*}{ Education } & No formal education & 23 & $3.28 \%$ \\
\hline & Primary (Elementary/MiddleSchool) & 111 & $15.83 \%$ \\
\hline & Secondary (High School) & 187 & $26.68 \%$ \\
\hline & University (Undergraduate) & 350 & $49.93 \%$ \\
\hline & Postgraduate & 30 & $4.28 \%$ \\
\hline
\end{tabular}




\begin{tabular}{llll}
\hline \multirow{2}{*}{ Prior Experience } & Expert $^{1}$ & 109 & $15.55 \%$ \\
\cline { 2 - 4 } & Novice $^{2}$ & 592 & $84.45 \%$ \\
\hline
\end{tabular}

Note: 1: Made 5 or more mobile payments in the last year. 2: Made less than 5 mobile payments in the last year.

\subsection{Research methodology and experimental design}

Statistical quantitative analysis of the results obtained was performed using SPSS 20 software.

The first stage of this process was to analyse the coded questions from the interviews discussed in the previous section. This analysis shows that the managers of respondent companies taking part in this research have a moderate level of knowledge and awareness regarding mobile payment systems (close to 65\%), a high level of perceived usefulness $(70.9 \%)$ and a moderate level of perceived trust (60\%). In view of these findings, intentions to use mobile payment systems would be expected to be moderate to high. However, the intention to use them was only reported by $21.5 \%$ of participants. This discrepancy highlights the timeliness of this research. Why are intentions to use P2PM-pay systems so low, given the acceptable levels of knowledge, awareness, usefulness and trust?

To address this inconsistency, these findings were analysed using logistic regression (LR) and a neural network model. The variables examined to define intention to adopt the new payment system were divided into two groups: behavioural variables (perceived ease of use, perceived risk, trust, personal innovativeness, subjective norms, perceived enjoyment, banking brand loyalty and perceived quality) and sociodemographic variables (sex and age).

Multiple behavioral decision theories and models of intention to use have been developed in the scientific literature in order to analyze the behavior of individuals in response to an innovation, the majority of which are based on social psychology studies. The theoretical framework of this study is based on the most extensively used theories and models in the field of marketing literature and information technology, specifically: Theory of Reasoned Action (TRA) from Fishbein \& Ajzen (1975), Technology Acceptance Model (TAM) from Davis et al. (1989), Theory of Planned Behavior (TPB) from Ajzen (1991), TAM 2 from Venkatesh \& Davis (2000), Unified Theory of Acceptance and Use of Technology (UTAUT) from Venkatesh et al. (2003), TAM 3 from Venkatesh \& Bala (2008), and UTAUT2 from Venkatesh et al. (2012). In recent years, new research has incorporated other variables that had not previously been considered in earlier models, specifically in regard to services offered through mobile devices and payment systems in particular (Renaud \& Van Biljon, 2008; Liébana-Cabanillas et al., 2014a; Di Pietro et al., 2015). In particular, in our research we propose the inclusion of the following variables: "Ease of use" refers to individuals' perception that using a certain system will be effortless and/or uncomplicated (Davis, 1989; Singh et al., 2020). "Perceived risk" is a multidimensional construct composed of various factors that jointly explain the global risk associated with the adoption and use of a payment service (Featherman \& Pavlou, 2003; Wu et al., 2017; Liébana-Cabanillas et al., 2019a). "Trust" is the psychological state reflecting favourable expectations of the intentions and behaviour of others (Singh \& Sirdeshmukh, 2000; Liébana-Cabanillas et al., 2019b). "Personal innovativeness" is the willingness to try new 
Table 2. Prior research addressing the variables examined through this study.

\begin{tabular}{|l|l|}
\hline Variable & Authors \\
\hline Perceived ease of use & Ramos-de-Luna et al. (2015); Shasrma et al. (2019); Ramos de Luna et al. (2019) \\
\hline Perceived risk & Jenkins and Ophoff (2016); Chen and Li (2017) \\
\hline Perceived usefulness & Ramos-de-Luna et al. (2015); Gbongli et al. (2019) \\
\hline Perceived trust & Khalilzadeh et al. (2017); Shen et al. (2017); Liébana-Cabanillas et al. (2019), \\
\hline Personal innovativeness & Ramos-de-Luna et al. (2015); Liébana-Cabanillas et al (2018); Gbongli et al. (2019) \\
\hline Subjective norms & Liébana-Cabanillas et al (2014 a,b,c); Ramos-de-Luna et al. (2015) \\
\hline Perceived enjoyment & Rouibah et al. (2016) \\
\hline Banking brand loyalty & Hossain (2019) \\
\hline Perceived quality & Almarashdeh (2018); Liébana-Cabanillas et al. (2019) \\
\hline
\end{tabular}

Source: Compiled by authors.

The sociodemographic variables considered (sex and age) establish the profile of potential and existing users. In this respect, our study includes the same categories as those used by the National Employment Institute in their statistical reports. Men and women are believed to have different commercial orientations, which are expressed through different patterns of behaviour (Swaminathan et al., 1999). Traditionally, men have been more willing to participate in ecommerce (Susskind, 2004); moreover, they are more likely to make planned purchases (electronic hardware and software), while women are more prone to make impulse purchases (food, drinks and clothes) (Zhou et al. 2007). In this context, the role of gender has been analysed since the late 1990s (Gefen \& Straub, 1997; Venkatesh \& Morris, 
2000). With respect to the possible use of P2PM-pay, studies have reported the influence of gender on the use of mobile phone chats (Nysveen et al., 2005), loyalty to internet operators (Sánchez-Franco et al., 2009), loyalty to banks (Floh \& Treiblmaier, 2006), the adoption of e-commerce (Hwang, 2010) and willingness to use mobile payments (Liébana-Cabanillas et al., 2014), among other areas of interest.

\subsubsection{Forecasting strategy and accuracy}

In theory, the nonparametric statistical technique implemented in this paper (multilayer perceptron, MLP) should be more accurate than the classical parametric method (logistic regression, LR), although there is empirical evidence that, depending on the sample taken, both approaches can achieve satisfactory results (Ravi Kumar \& Ravi, 2007; Olson et al., 2012). This theoretical superiority is assumed from the high complexity, computational power and learning capacity associated with nonparametric approaches. However, the transparency of LR models in terms of the selection of variables and of the temporal structure adds flexibility, which allows the researcher to adapt the model according to the study goals (Rodrigues \& Stevenson, 2013). Therefore, the use of a joint approach, combining parametric and nonparametric techniques, is expected to minimise the theoretical problems of each one and to provide valuable synergies between them.

To test the above concepts, we constructed a two-stage model to predict the use of P2P payment. The main purpose of the LR model was to predict the outcome category for individual cases, using the most parsimonious model. To do so, the model included all the variables expected to be useful in determining the dependent variable. These were introduced into the model by stepwise regression, following the order established in previous research, and testing the fit of the model after the inclusion of each coefficient. The inclusion of appropriate variables in the parametric model (Logistic Regression) enabled us to determine the empirical relationship between these predictors and the probability of P2P payments being used (through the signs of their coefficients). We then developed the MLP neural network and compared it to the classical parametric technique (Leong et al., 2018). Neural networks are particular, implicitly limited, implementations of ordinary smoothers, which are the non-linear, not necessarily additive extensions of the logistic regression model (Blanco et al., 2013; Cubiles-De-La-Vega et al., 2013). Finally, we describe the statistical characteristics of the best prediction models obtained.

The area under the ROC curve (AUC) is often used in classification problems, and in this study it was calculated using the SPSS 23 statistical package. However, in order to assess the overall prediction capacity of a model, the a priori probabilities and the costs of misclassification must also be considered (West, 2000). According to West (2000), the relative proportion of costs associated with Type I classification errors (i.e. when an individual not using P2P payment is classified as one using P2P payment) and Type II (vice versa) errors should be 1:5, and therefore special attention must be paid to Type II errors in any model that is built. The function that calculates the cost of each type of classification error is expressed as follows:

$$
\text { Cost }=C_{21} P_{21} \pi_{1}+C_{12} P_{12} \pi_{2}
$$


where $\pi_{1}$ and $\pi_{2}$ are the prior probabilities of not using P2P payment and of using P2P payment, respectively; $\mathrm{P}_{21}$ and $\mathrm{P}_{12}$ measure the probability of occurrence of Type I and Type II errors, respectively, and $\mathrm{C}_{21}$ and $\mathrm{C}_{12}$ are the misclassification costs of Type I and Type II errors, respectively.

\subsubsection{Logistic regression model}

Analysis of the characteristics of the study sample revealed a significant presence of categorical explanatory variables. For this reason, among others, we used binary LR to devise a model in which the response (or dependent variable) is a dummy with a value of 0 when P2P payment is not used, and a value of 1 when it is. The LR model is formulated as follows:

$$
\log \left(\frac{p}{1-p}\right)=\beta_{0}+\beta_{1} x_{1}+\beta_{2} x_{2}+\ldots . .+\beta_{k} x_{k}
$$

where $p$ is the probability of occurrence of $\mathrm{P} 2 \mathrm{P}$ payment. Given the value of the independent variables, this probability can be calculated directly as follows:

$$
p=\frac{e^{Z}}{1+e^{Z}}=\frac{1}{1+e^{-Z}}
$$

where:

$$
Z=\beta_{0}+\beta_{1} x_{1}+\beta_{2} x_{2}+\ldots . .+\beta_{k} x_{k}
$$

Various inference procedures can be used to test the statistical significance of the model and the individual importance of each variable. In fact, LR can be fully integrated into a decision-making context, but to enable comparison with the other models, a probability threshold must be set to classify users of the application as 0 or 1 . Thus, given the 99 possible values for this probability threshold $(0.01,0.02, \ldots, 0.99)$ we selected the one that minimised the 10 -fold validation error (Blanco et al., 2013), thus obtaining 0.49 .

A drawback of LR is that it requires a larger quantity of data in order to obtain stable results, and in some cases, the independent variables must be transformed in order to consider the complex nonlinear relationships between them and the dependent variable.

\subsubsection{Artificial neural networks model}

Artificial neural networks (ANNs) provide a computational paradigm and form the basis for a wide variety of nonlinear mathematical models that can be applied to many statistical problems (Blanco et al., 2013).

Theoretical studies have led to a particular architecture, that of multilayer perceptrons (MLP), becoming a referencestandard procedure in the family of nonparametric models (Bishop, 1995). Moreover, MLP is the commonest ANN 
used in commercial studies (Vellido et al., 1999; Zhang et al., 1998). Taking into account this background, we employed a three-layer perceptron in which the output layer was formed by a node that provided the estimated probability of use of P2P payment. This value is calculated by the logistic activation function $g(u)=e^{u} /\left(e^{u}+1\right)$, which is also used in the hidden layer. We denote the size of this hidden layer as $\mathrm{H}$, the synaptic weights for the connections between the p-size input and the hidden layer as $\left\{v_{i h}, i=0,1,2, \ldots, p, h=1,2, \ldots, H\right\}$, and the synaptic weights for the connections between the hidden nodes and the output node as $\left\{w_{h}, h=0,1,2, \ldots, H\right\}$. Then, the output of the neural network assuming an input vector $\left(x_{1}, \ldots, x_{p}\right)$ is expressed as

$$
\hat{y}=g\left(w_{0}+\sum_{h=1}^{H} w_{h} g\left(v_{0 h}+\sum_{j=1}^{p} v_{i h} x_{j}\right)\right)
$$

The output from this model provides an estimate of the probability of use of $\mathrm{P} 2 \mathrm{P}$ payment for the corresponding input vector. The final decision can be obtained by comparing this result with a threshold, usually set at 0.5 , and the noncompliance condition is established if $\hat{y}>0.5$.

A major problem with MLP is the fact that there is no known procedure to ensure that a global solution can be found for the problem of finding a synaptic weight configuration that minimises the usual error criteria. In consequence, the choice of any one criterion among the many possibilities is often made in accordance with the various learning rules that have been proposed. Another drawback is its black box nature, which makes it very difficult to interpret the resulting model, although certain useful proposals in this respect have been made, such as Bayesian neural networks (Neal, 1996).

There is no general rule for determining the optimal number of hidden nodes, a parameter that is necessary for optimal network performance (Kim, 2003). The most common way of determining the size of the hidden layer is through experiments or trial and error (Tang \& Fishwick, 1993; Wong, 1991). Figure 1 illustrates the typical structure of an MLP model. The number of hidden nodes determines the complexity of the final model, and networks of a more complex nature do not guarantee better generalisation. One strategy that is widely accepted consists of selecting the size of the hidden layer $(\mathrm{H})$ according to the results of a validation study (Hastie et al., 2001). Therefore, we selected (H) following a 10-fold cross-validation search in $\{1,2, \ldots, 20\}$. Finally, for classification problems, an appropriate error function is fitting by conditional maximum likelihood (or entropy) (Hastie et al., 2001). 
Figure 1. Three-layer multilayer perceptron

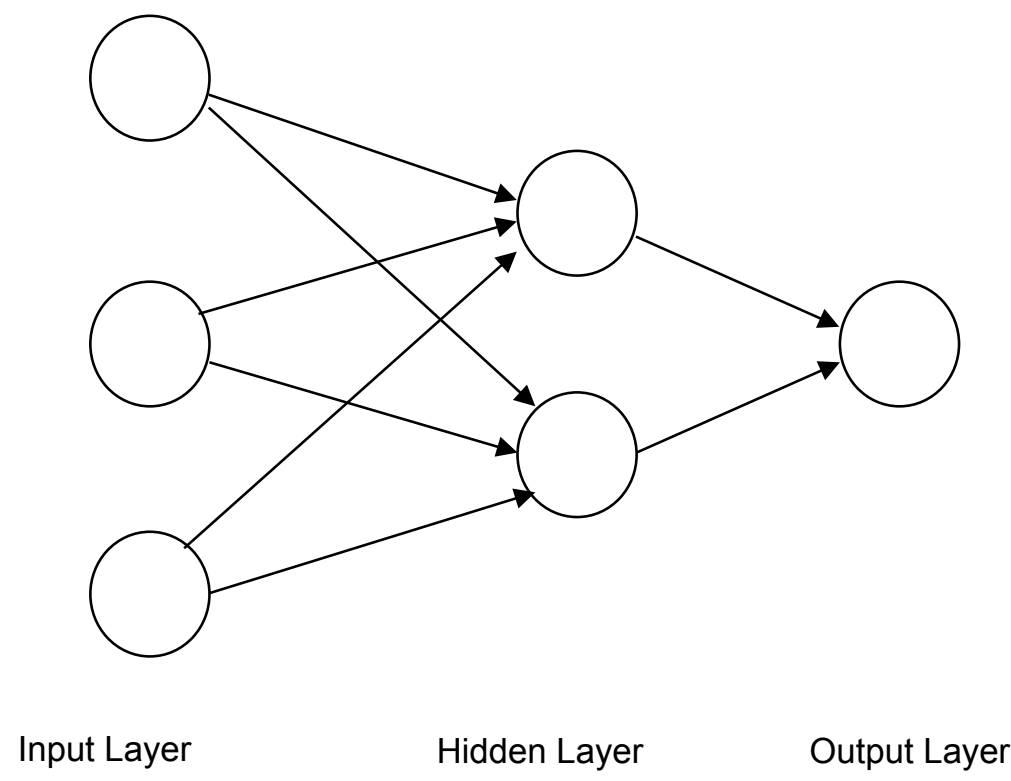

\section{RESULTS AND DISCUSSION}

Following Jones (1987), we reserved a random sample of $20 \%$ for validation and to measure the performance of the study models.

From the LR results obtained (Table 3) we conclude that six variables significantly influence intentions to use P2P payment: ease of use, perceived risk, personal innovativeness, perceived usefulness, subjective norms and perceived enjoyment.

The variable "ease of use" was found to be inversely related to the use of P2P payment, showing that perceived difficulty in using the application will decrease the probability of its use. The perceived risk presented a positive sign, indicating that the greater the perceived risk in using P2P payment, the lower the probability of its use. The relationship between P2P payment and personal innovativeness also presented a positive sign. Similarly, the greater the perceived usefulness of the application, the higher the probability of its being used. The variable "subjective norms" is inversely related to $\mathrm{P} 2 \mathrm{P}$ payment, and so the greater the number of such restrictions, the lower the probability of the application being used. Finally, there is a significant positive relationship between perceived enjoyment and the probability of using P2P payment.

These findings represent a significant advance on previous research in this field of knowledge (Liébana-Cabanillas et al., 2019a; Humbani, and Wiese, 2019) which approaches the importance of the mobile payment platforms but generally disregards intention to use P2P payments. Absent variables from the extant literature such as perceived risk, personal innovativeness, and subjective norms have a major statistical significance along with sizable impact on 
intention to use mobile payments. Results from the present study evidence logic causal relationships between the aforementioned variables and the dependent variable.

Table 3. Variables included in the final model

\begin{tabular}{|c|c|c|c|c|c|c|}
\hline \multicolumn{5}{|c|}{ Logistic Regression model } & \multicolumn{2}{|c|}{$95 \%$ C.I. for $\operatorname{Exp}(\beta)$} \\
\hline Variable & Coef. ( $\beta$ ) & Std. Err. & Wald & $\operatorname{Exp}(\beta)$ & Lower & Upper \\
\hline PEOU1(1) & -1.138 & 0.321 & 12.601 & 0.320 & 0.171 & 0.601 \\
\hline PR1(1) & 0.855 & 0.196 & 18.965 & 2.351 & 1.600 & 3.455 \\
\hline PII1(1) & -0.587 & 0.207 & 8.031 & 0.556 & 0.371 & 0.834 \\
\hline PU1(1) & -1.257 & 0.234 & 28.881 & 0.284 & 0.180 & 0.450 \\
\hline $\mathrm{SN} 1(1)$ & -1.107 & 0.319 & 12.076 & 0.330 & 0.177 & 0.617 \\
\hline PENJ1(1) & -1.073 & 0.392 & 7.489 & 0.342 & 0.159 & 0.738 \\
\hline Constant & 2.801 & 0.389 & 51.879 & 16.457 & & \\
\hline \multicolumn{7}{|c|}{ Log likelihood: 678.79} \\
\hline \multicolumn{7}{|c|}{ Wald Chi-square: 502.07 ; sig.: 0.000} \\
\hline \multicolumn{7}{|c|}{ Chi-square: 387.74 ; sig.: 0.000} \\
\hline
\end{tabular}

Although no empirical evidence was found of any significant relationship between the remaining variables and the use of P2P payment, the MLP neural network showed all the variables to have some effect. However, examination of the weights of each variable, according to MLP (see Table 4) shows there are greater weights for the variables found to be significant in the LR model, which suggests that the significant variables discussed above best explain the use of P2P payment. 
Table 4. Weights of the variables in the neural network model

\begin{tabular}{|c|c|c|c|c|c|c|c|c|c|c|c|}
\hline \multirow{3}{*}{ Predictor } & & \multicolumn{10}{|c|}{ Predicted } \\
\hline & & \multicolumn{7}{|c|}{ Hidden Layer 1} & \multicolumn{3}{|c|}{ Output Layer } \\
\hline & & H(1:1) & H(1:2) & H(1:3) & H(1:4) & H(1:5) & H(1:6) & H(1:7) & H(1:8) & {$[\mathbf{Y}=\mathbf{0}]$} & {$[Y=1]$} \\
\hline \multirow{32}{*}{$\begin{array}{l}\text { Input } \\
\text { Layer }\end{array}$} & (Bias) & -0.306 & 0.441 & -0.224 & 0.201 & -0.447 & -0.218 & -0.468 & -0.028 & & \\
\hline & LOY1 & -0.264 & -0.260 & -0.081 & -0.185 & -0.339 & 0.155 & -0.322 & -0.206 & & \\
\hline & LOY2 & 0.155 & -0.348 & 0.023 & -0.166 & -0.337 & -0.359 & -0.277 & 0.311 & & \\
\hline & LOY3 & 0.374 & -0.419 & -0.224 & 0.190 & 0.132 & 0.001 & 0.049 & -0.179 & & \\
\hline & LOY4 & -0.363 & 0.039 & 0.086 & -0.019 & 0.105 & -0.316 & -0.282 & -0.399 & & \\
\hline & PEOU1 & -0.139 & 0.450 & -0.292 & -0.217 & -0.400 & 0.029 & -0.239 & 0.400 & & \\
\hline & PEOU2 & -0.337 & -0.356 & -0.255 & -0.029 & 0.066 & 0.243 & 0.438 & -0.360 & & \\
\hline & PEOU3 & 0.456 & 0.391 & 0.261 & 0.086 & 0.336 & 0.358 & -0.277 & -0.218 & & \\
\hline & PEOU4 & -0.164 & 0.473 & -0.178 & 0.347 & -0.095 & -0.219 & -0.242 & 0.218 & & \\
\hline & PEOU5 & -0.251 & 0.074 & -0.093 & 0.411 & 0.114 & -0.317 & -0.367 & -0.151 & & \\
\hline & PR1 & -0.210 & -0.070 & -0.090 & 0.296 & -0.244 & -0.497 & -0.474 & -0.486 & & \\
\hline & PR2 & 0.366 & 0.282 & -0.207 & -0.317 & 0.406 & 0.167 & -0.039 & 0.320 & & \\
\hline & PR3 & 0.113 & -0.358 & 0.373 & 0.265 & 0.488 & -0.226 & 0.267 & -0.529 & & \\
\hline & PR4 & -0.420 & -0.324 & -0.260 & -0.034 & 0.193 & 0.404 & -0.438 & 0.045 & & \\
\hline & PII1 & 0.230 & -0.438 & 0.409 & 0.161 & 0.464 & -0.203 & -0.475 & -0.135 & & \\
\hline & PII2 & -0.197 & 0.260 & 0.458 & -0.323 & 0.182 & 0.342 & -0.012 & -0.130 & & \\
\hline & PII3 & -0.190 & -0.197 & 0.423 & -0.519 & -0.463 & -0.396 & 0.321 & 0.189 & & \\
\hline & PII4 & 0.305 & 0.224 & $\begin{array}{l}-0.303 \\
\end{array}$ & 0.308 & 0.216 & -0.108 & 0.109 & 0.002 & & \\
\hline & PU1 & 0.283 & 0.270 & 0.423 & -0.201 & 0.131 & 0.507 & -0.165 & -0.027 & & \\
\hline & PU2 & -0.340 & -0.342 & 0.058 & -0.021 & -0.029 & 0.518 & -0.219 & 0.088 & & \\
\hline & PU3 & -0.050 & -0.129 & 0.448 & -0.040 & 0.272 & -0.055 & -0.095 & 0.392 & & \\
\hline & PU4 & -0.501 & -0.447 & 0.214 & -0.023 & -0.204 & 0.167 & 0.343 & 0.260 & & \\
\hline & QUAL1 & 0.388 & -0.380 & 0.298 & -0.294 & 0.051 & 0.245 & -0.347 & 0.389 & & \\
\hline & QUAL2 & -0.221 & -0.323 & -0.421 & -0.100 & 0.229 & 0.339 & 0.266 & 0.483 & & \\
\hline & QUAL3 & 0.435 & -0.253 & -0.231 & 0.166 & -0.429 & -0.293 & -0.477 & 0.177 & & \\
\hline & QUAL4 & 0.154 & -0.291 & 0.486 & 0.347 & -0.252 & -0.426 & -0.125 & 0.032 & & \\
\hline & QUAL5 & 0.339 & 0.089 & 0.375 & -0.364 & 0.414 & 0.081 & -0.333 & 0.327 & & \\
\hline & QUAL6 & 0.166 & 0.038 & 0.183 & 0.226 & 0.405 & 0.346 & -0.432 & 0.164 & & \\
\hline & QUAL7 & -0.110 & -0.170 & 0.208 & 0.003 & -0.090 & 0.316 & -0.159 & -0.307 & & \\
\hline & SN1 & 0.440 & 0.267 & 0.191 & $-\mathbf{0 . 3 5 7}$ & 0.027 & -0.205 & 0.454 & -0.287 & & \\
\hline & SN2 & -0.258 & -0.490 & 0.258 & -0.208 & 0.276 & 0.422 & -0.089 & 0.206 & & \\
\hline & SN3 & 0.279 & -0.224 & 0.031 & -0.266 & -0.033 & 0.357 & 0.180 & -0.024 & & \\
\hline
\end{tabular}




\begin{tabular}{|c|c|c|c|c|c|c|c|c|c|c|c|}
\hline \multirow{3}{*}{ Predictor } & & \multicolumn{10}{|c|}{ Predicted } \\
\hline & & \multicolumn{7}{|c|}{ Hidden Layer 1} & \multicolumn{3}{|c|}{ Output Layer } \\
\hline & & H(1:1) & H(1:2) & H(1:3) & H(1:4) & H(1:5) & H(1:6) & H(1:7) & H(1:8) & {$[\mathbf{Y}=\mathbf{0}]$} & {$[\mathbf{Y}=\mathbf{1}]$} \\
\hline & SN4 & -0.429 & -0.237 & 0.522 & -0.480 & -0.329 & 0.466 & -0.059 & -0.467 & & \\
\hline & TR1 & 0.238 & -0.115 & -0.288 & -0.239 & 0.199 & 0.152 & 0.362 & -0.262 & & \\
\hline & TR2 & 0.391 & 0.001 & -0.309 & -0.192 & 0.313 & 0.008 & -0.169 & 0.146 & & \\
\hline & TR3 & 0.310 & 0.191 & -0.295 & -0.325 & -0.437 & 0.227 & -0.510 & 0.257 & & \\
\hline & TR4 & -0.214 & -0.223 & -0.009 & -0.342 & 0.251 & 0.060 & 0.088 & 0.457 & & \\
\hline & PENJ1 & 0.128 & -0.099 & -0.114 & -0.093 & -0.252 & -0.434 & 0.337 & 0.534 & & \\
\hline & PENJ2 & 0.010 & -0.281 & 0.245 & -0.221 & -0.340 & -0.121 & 0.294 & 0.490 & & \\
\hline & PENJ3 & -0.341 & 0.371 & 0.416 & -0.472 & 0.150 & -0.389 & -0.145 & -0.162 & & \\
\hline & GENDER & 0.105 & -0.291 & -0.236 & 0.262 & 0.287 & 0.114 & 0.092 & 0.251 & & \\
\hline & $\mathrm{AGE}$ & -0.414 & -0.105 & -0.312 & 0.438 & 0.041 & 0.311 & 0.167 & 0.403 & & \\
\hline \multirow{8}{*}{$\begin{array}{l}\text { Hidden } \\
\text { Layer } 1\end{array}$} & (Bias) & & & & & & & & & -0.377 & -0.062 \\
\hline & $\mathrm{H}(1: 1)$ & & & & & & & & & 0.217 & -0.011 \\
\hline & $\mathrm{H}(1: 3)$ & & & & & & & & & -0.184 & 0.540 \\
\hline & $\mathrm{H}(1: 4)$ & & & & & & & & & 0.129 & -0.415 \\
\hline & $\mathrm{H}(1: 5)$ & & & & & & & & & 0.156 & -0.057 \\
\hline & $\mathrm{H}(1: 6)$ & & & & & & & & & -0.202 & -0.033 \\
\hline & $\mathrm{H}(1: 7)$ & & & & & & & & & 0.302 & 0.191 \\
\hline & $\mathrm{H}(1: 8)$ & & & & & & & & & -0.154 & 0.722 \\
\hline
\end{tabular}


According to the above results, the classification accuracy is $72.47 \%$ with a sensitivity of $67.72 \%$ and a specificity of $72.12 \%$ for an optimal cut-off point of 0.49 (see Table 5). The classification matrix values obtained by the neural network reveal a classification accuracy of $80.31 \%$ with sensitivity and specificity values of $77.47 \%$ and $82.76 \%$, respectively.

Table 5. Classification matrix

Logistic regression

\begin{tabular}{cccc}
\hline \multirow{2}{*}{ Observ. } & \multicolumn{3}{c}{ Prediction } \\
\cline { 2 - 4 } & 0 & 1 & $\begin{array}{c}\text { Correct } \\
\text { Classification }\end{array}$ \\
\hline 0 & 235 & 81 & $74.37 \%$ \\
1 & 112 & 273 & $70.91 \%$ \\
\hline Sens & $67.72 \%$ & $72.47 \%$ \\
\hline Spec & $77.12 \%$ \\
\hline \multicolumn{4}{c}{ Neural network } \\
\hline \multicolumn{4}{c}{ Prediction } \\
Observ. & 0 & 1 & Correct \\
\cline { 2 - 4 } 0 & 251 & 65 & $79.43 \%$ \\
1 & 73 & 312 & $81.04 \%$ \\
\hline Sens & $77.47 \%$ & $80.31 \%$ \\
\hline Spec
\end{tabular}

The performance of each model was evaluated according to the AUC, following standard practice in classification problems (Řezáč \& Řezáč, 2011). Table 6 summarises the results obtained for AUC, test accuracy and Type I-Type II errors, for the two models tested, for the training samples and the test samples. This analysis is illustrated by the ROC curve, which provides a graphical representation of the sensitivity and specificity values (Figure 2).

With respect to the nonparametric technique, Table 5 shows that the MLP prediction model for the use of P2P payment obtains higher AUC values, and thus is more accurate, than the LR model. We note that the MLP model uses the Levenberg-Marquardt training algorithm, built with eighteen hidden nodes, and produces a sum squared error of 0.174 . Taking into account the costs of misclassification (Table 7), these results continue to suggest that the neural network performs better than a LR parametric model. 
Table 6. AUC, Type I errors and Type II errors

\begin{tabular}{ccccccccc}
\hline & \multicolumn{3}{c}{ Training sample (80\%) } & \multicolumn{3}{c}{ Test sample (20\%) } \\
\hline $\begin{array}{c}\text { Statistical } \\
\text { technique }\end{array}$ & AUC & $\begin{array}{c}\text { Test } \\
\text { accuracy }\end{array}$ & Type I & $\begin{array}{c}\text { Type } \\
\text { II }\end{array}$ & AUC & $\begin{array}{c}\text { Test } \\
\text { accuracy }\end{array}$ & Type I & $\begin{array}{c}\text { Type } \\
\text { II }\end{array}$ \\
\hline $\begin{array}{c}\text { Logistic } \\
\text { regression }\end{array}$ & 0.781 & $78.51 \%$ & $26.71 \%$ & $30.64 \%$ & 0.777 & $77.89 \%$ & $26.83 \%$ & $31.09 \%$ \\
\hline $\begin{array}{c}\text { Multilayer } \\
\text { perceptron }\end{array}$ & 0.830 & $82.21 \%$ & $24.29 \%$ & $27.41 \%$ & 0.827 & $82.20 \%$ & $24.41 \%$ & $27.77 \%$ \\
\hline
\end{tabular}

Table 7. Costs of misclassification

\begin{tabular}{ccc}
\hline $\begin{array}{c}\text { Statistical } \\
\text { Technique }\end{array}$ & $\begin{array}{c}\text { Misclassification cost } \\
\text { (Training sample) }\end{array}$ & $\begin{array}{c}\text { Misclassification cost } \\
\text { (Test sample) }\end{array}$ \\
\hline $\begin{array}{c}\text { Logistic } \\
\text { regression }\end{array}$ & 0.8731 & 0.8630 \\
\hline Multilayer & 0.7771 & 0.7799 \\
Perceptron & & \\
\hline
\end{tabular}

As mentioned above, the misclassification costs presented in Table 6 were calculated by assuming a ratio of 1:5 (West, 2000). We suggest, in line with other authors (Angelini et al., 2008; Neves \& Vieira, 2006; Wilson \& Sharda, 1994), that MLP models tend to have higher AUC values and lower misclassification costs than traditional LR models. Our empirical results confirm the theoretical superiority of this approach with respect to adaptive properties of nonlinear and nonparametric learning in the development of predictive models of the use of $\mathrm{P} 2 \mathrm{P}$ payment. Therefore, we suggest that marketing professionals and users of this information should prefer MLP-based models over traditional parametric ones, since a small improvement in the predictive capacity of the model may be of great importance to the balance sheets of banks that offer P2P payment methods.

These findings represent a major contribution advance on previous research (Blanco et al., 2013; Cubiles-De-La-Vega et al., 2013; Vellido et al., 1999; Zhang et al., 1998) while proving that artificial neural networks yield vastly improved results with regard to model evaluation measures and classification compared with traditional parametric methods.

Finally, the obtained results also are especially significant for the decision-making process of bank managers. In this sense, they are required to keep up to date with the factors impacting P2P payment systems' intention to use. The trend set by these factors and variables should serve as a decision-making starting point in order to achieve an improved mobile banking customer reach and more efficient m-payment systems. 

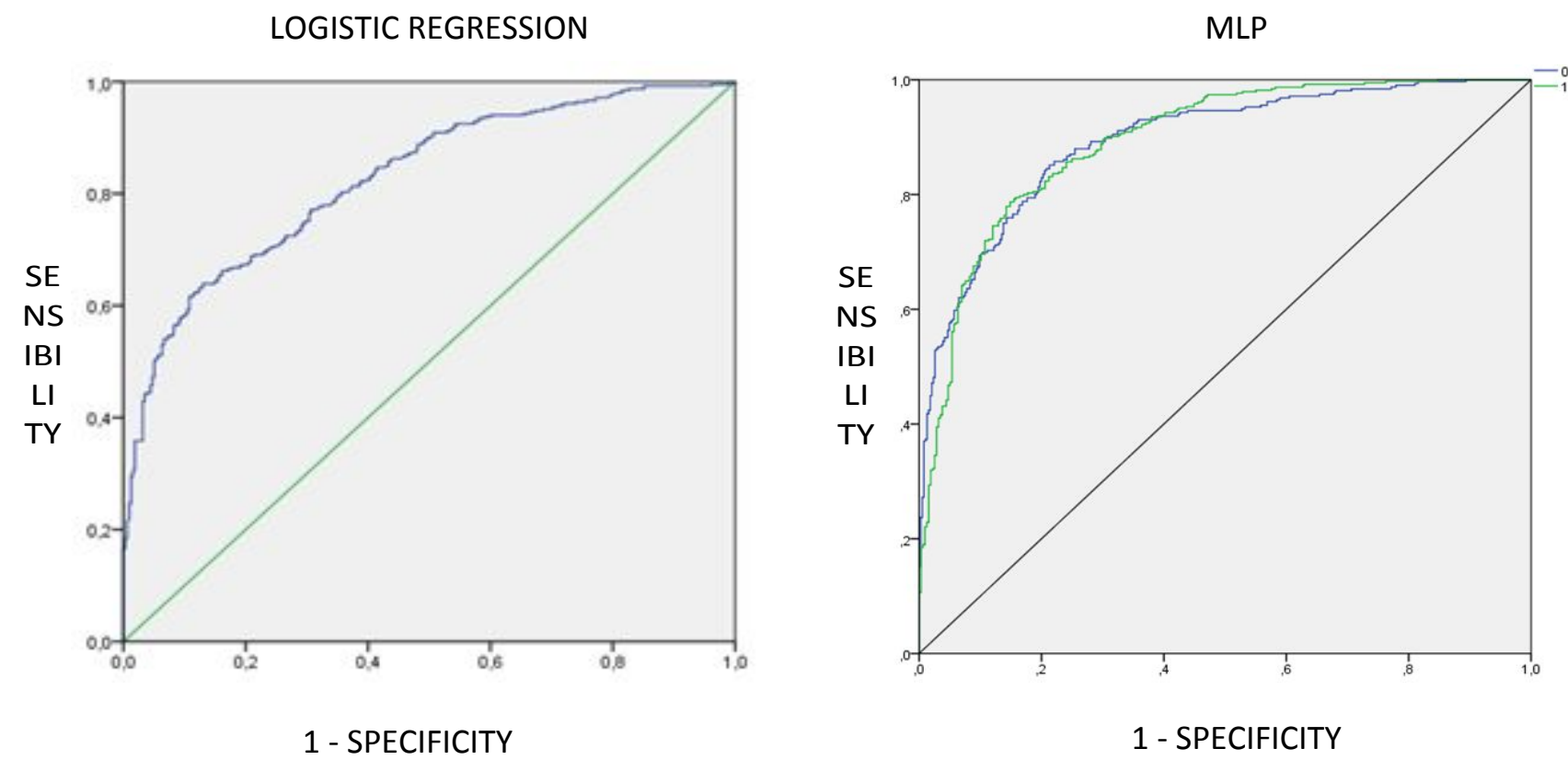

\section{LIMITATIONS, RECOMMENDATIONS AND AVENUES FOR FUTURE RESEARCH}

Since the obtained results represent a breakthrough in the extant literature and are especially significant for policymaking actors, the primary beneficiaries from the present study would be banks and their managers. Firstly, this research found evidence that previously overlooked variables in the literature have a distinct effect on P2P payment systems' intention to use. In this vein, perceived risk and subjective norms proved to be barriers to the approach to these systems. On the other hand, perceived personal innovativeness is positively related to the use of P2P payment methods.

Secondly, the present research illustrates how neural networks yield a vastly improved performance compared to traditional parametric predictive models approached by previous studies in the literature.

Despite its significant contributions, this study has some limitations, and these provide fruitful avenues for future research.

First, the sample used in this study was composed of a panel of Spanish users of mobile services. It would be useful to extend this analysis to other countries and to perform comparative cultural studies to detect possible differences in this respect and to lend greater consistency to the results obtained. 
Furthermore, our method of data collection was based on a cross-sectional design, and so it was not possible to analyse the evolution of user behaviour over time. A longitudinal design would have allowed us to test the strength of the relationships observed and to verify their evolution over time.

The conclusions drawn from this research, together with its inherent limitations, can provide a fruitful basis for future studies concerning the intention to adopt mobile payment systems.

In this regard, future studies could complement our research by incorporating actual data on the use of mobile payment instruments and by comparing results with analyses in which this information is not taken into account. Thus, researchers would be able to obtain and analyse specific quantitative measurements.

Moreover, with real data on the use of P2P payment systems, the relationships identified in our LR analysis and in the proposed neural network could be corroborated. To enhance the consistency of the results obtained, this research could be repeated in successive years to verify the experience effect, to review the results and to highlight changes in variables and relationships.

Finally, a valuable area for future research would be to explore the perception and influence of external elements (for example, security seals, providers' brands and logos) on variables such as knowledge, trust and perceived security regarding these payment methods, analysing their influence on the intention to use.

\section{REFERENCES}

Agarwal, R. \& Karahanna, E. (1998). On the multi-dimensional nature of compatibility beliefs in technology acceptance. In Proceedings of the 19th Annual International Conference on Information Systems (pp. 13-16).

Agarwal, R. \& Karahanna, E. (2000). Time flies when you're having fun: Cognitive absorption and beliefs about information technology usage. MIS Quarterly, 665-694.

Agarwal, R. \& Prasad, J. (1998). A conceptual and operational definition of personal innovativeness in the domain of information technology. Information Systems Research, 9(2), 204-215.

Ajzen, I. (1991). The theory of planned behavior. Organizational behavior and human decision processes, 50(2), 179-211.

Almarashdeh, I. (2018). The important of service quality and the trust in technology on users perspectives to continues use of mobile services. Journal of Theoretical \& Applied Information Technology, 96(10).

Angelini, E., di Tollo, G. \& Roli, A. (2008). A neural network approach for credit risk evaluation. The Quarterly Review of Economics and Finance, 48(4), 733-755.

Bansal, S., Bruno, P. et al (2015). How the payments industry is being disrupted. McKinsey \& Company, Washington, DC http:// http://www.mckinsey.com/industries/financial-services/our-insights/how-the-payments-industry-is-beingdisrupted 
Berman, S. J. (2012). Digital transformation: opportunities to create new business models. Strategy \& Leadership, 40(2), 1624.

Bhattacherjee, A. \& Premkumar, G. (2004). Understanding changes in belief and attitude toward information technology usage: A theoretical model and longitudinal test. MIS Quarterly, 229-254.

Bishop, C.M. (1995). Neural networks for pattern recognition. New York: Oxford University Press.

Bizum (2017a). Bizum alcanza el medio millón de usuarios. Retrieved from: https://bizum.es/area-de-prensa/. Last accessed: Feb 1 $1^{\text {st }}, 2018$

Bizum (2017b). Sobre nostros. Retrieved from: https://bizum.es/sobre-nosotros/. Last accessed: Feb 1' 2018

Blanco, A., Pino-Mejías, R., Lara, J. \& Rayo, S. (2013). Credit scoring models for the microfinance industry using neural networks: evidence from Peru. Expert System With Application. 40(1), 356-364.

Blanco, J.M., (2017, February $3^{\text {rd }}$ ). De Yaap a Bizum y Verse: el cuento de los pagos móviles aún busca su final feliz. Retrieved from: http://www.eldiario.es/hojaderouter/tecnologia/moviles/pagos_moviles-Yaap-Verse-Bizum-apps-Espanafintech_0_608589170.html. Last accessed: Feb $1^{\text {st }}, 2018$

Brislin, R. W. (1970). Back-translation for cross-cultural research. Journal of Cross-Cultural Psychology, 1(3), 185-216.

Cai, S., Lin, X., Xu, D., \& Fu, X. (2016). Judging online peer-to-peer lending behavior: A comparison of first-time and repeated borrowing requests. Information \& Management, 53(7), 857-867.

Chen, X., \& Li, S. (2017). Understanding continuance intention of mobile payment services: an empirical study. Journal of Computer Information Systems, 57(4), 287-298.

Cohan, P.S., (2013, September $\left.5^{\text {th }}\right)$. What PayPal's rocky beginnings can teach you about startup success. Entrepreneur. Retrieved from: https://www.entrepreneur.com/article/228206. Last accessed: Feb 1'st, 2018

Dapp, T. F., Slomka, L., AG, D. B. \& Hoffmann, R. (2015). Fintech reloaded-Traditional banks as digital ecosystems. Publication of the German original.

Davis, F. D. (1989). Perceived usefulness, perceived ease of use, and user acceptance of information technology. MIS Quarterly, 319-340.

Davis, F. D., Bagozzi, R. P., \& Warshaw, P. R. (1989). User acceptance of computer technology: a comparison of two theoretical models. Management science, 35(8), 982-1003.

Denecker, O., Gulati, S. \& Niederkorn, M. (2014). The digital battle that banks must win. McKinsey \& Company, Washington, DC http://www.mckinsey.com/insights/financial_services/the_digital_battle_that_banks_must_win 
Di Pietro, L., Mugion, R. G., Mattia, G., Renzi, M. F., \& Toni, M. (2015). The Integrated Model on Mobile Payment Acceptance (IMMPA): An empirical application to public transport. Transportation Research Part C: Emerging Technologies, $56,463-479$.

eBay (2002, July $8^{\text {th }}$ ). eBay to acquire PayPal - shared mission will expand platforms and benefit consumers. Retrieved from: https://investors.ebayinc.com/releasedetail.cfm?releaseid=84142. Last accessed: Feb $1^{\text {st }}, 2018$

Featherman, M. S. \& Pavlou, P. A. (2003). Predicting e-services adoption: a perceived risk facets perspective. International Journal Of Human-Computer Studies, 59(4), 451-474.

Fishbein, M. \& Ajzen, I. (1975). Belief, attitude, intention and behavior: An introduction to theory and research.

Floh, A. \& Treiblmaier, H. (2006). What keeps the e-banking customer loyal? A multigroup analysis of the moderating role of consumer characteristics on e-loyalty in the financial service industry.

Gbongli, K., Xu, Y., \& Amedjonekou, K. M. (2019). Extended Technology Acceptance Model to Predict Mobile-Based Money Acceptance and Sustainability: A Multi-Analytical Structural Equation Modeling and Neural Network Approach. Sustainability, 11(13), 3639.

Gefen, D. \& Straub, D. W. (2004). Consumer trust in B2C e-Commerce and the importance of social presence: experiments in e-Products and e-Services. Omega, 32(6), 407-424.

Gefen, D., Karahanna, E. \& Straub, D. W. (2003). Trust and TAM in online shopping: An integrated model. MIS Quarterly, 27(1), 51-90.

Gözükara, İ. \& Çolakoğlu, N. (2016). A research on Generation Y students: brand innovation, brand trust and brand loyalty. International Journal of Business Management \& Economic Research, 7(2), 603-611.

Guillén, A., Herrera, L. J., Pomares, H., Rojas, I., \& Liébana-Cabanillas, F. (2016). Decision support system to determine intention to use mobile payment systems on social networks: A methodological analysis. International Journal of Intelligent Systems, 31(2), 153-172.

Haddad, C. \& Hornuf, L. (2016). The emergence of the global fintech market: Economic and technological determinants

Hastie, T., Tibshirani, R. \& Friedman, J.H. (2001). The elements of statistical learning: data mining, inference, and prediction. New York: Springer.

Hossain, M. A. (2019). Security perception in the adoption of mobile payment and the moderating effect of gender. PSU Research Review.

Humbani, M., \& Wiese, M. (2019). An integrated framework for the adoption and continuance intention to use mobile payment apps. International Journal of Bank Marketing, 37(2), 646-664. 
Hwang, Y. (2010). The moderating effects of gender on e-commerce systems adoption factors: An empirical investigation. Computers in Human Behavior, 26(6), 1753-1760.

Jarvenpaa, S. L., Tractinsky, N. \& Vitale, M. (2000). Consumer trust in an Internet store. Information technology and management, 1(1-2), 45-71.

Javelin (2015). Mobile P2P Projected to skyrocket in the next five years $180 \%$. Available in https://www.javelinstrategy.com/press-release/mobile-p2p-projected-skyrocket-next-five-years-180 Last accessed: Feb $1^{\text {st }}, 2018$

Jenkins, P., \& Ophoff, J. (2016, January). Factors influencing the intention to adopt NFC mobile payments-A South African perspective. In CONF-IRM (p. 45).

Jones F.L. (1987). Current techniques in bankruptcy prediction. Journal of Accounting Literature, 6, 131-164.

Kalinic, Z., Marinkovic, V., Molinillo, S., \& Liébana-Cabanillas, F. (2019). A multi-analytical approach to peer-to-peer mobile payment acceptance prediction. Journal of Retailing and Consumer Services, 49, 143-153.

Kane, G. et al. (2015, July 14th). MIT Sloan Management Review, Strategy, not Technology drives digital transformation. Retrieved from: http://sloanreview.mit.edu/projects/strategy-drives-digital-transformation/. Last accessed: Aug 1st, 2017

Khalilzadeh, J., Ozturk, A. B., \& Bilgihan, A. (2017). Security-related factors in extended UTAUT model for NFC based mobile payment in the restaurant industry. Computers in Human Behavior, 70, 460-474.

Kim, K. J. (2003). Financial time series forecasting using support vector machines. Neurocomputing, 55(1-2), 307-319.

Kim, M., Kim, S., \& Kim, J. (2019). Can mobile and biometric payments replace cards in the Korean offline payments market? Consumer preference analysis for payment systems using a discrete choice model. Telematics and Informatics, 38, 46-58.

Kujala, S., Mugge, R., \& Miron-Shatz, T. (2017). The role of expectations in service evaluation: A longitudinal study of a proximity mobile payment service. International Journal of Human-Computer Studies, 98, 51-61.

Lai, F., Hutchinson, J., Li, D. \& Bai, C. (2007). An empirical assessment and application of SERVQUAL in mainland China's mobile communications industry. International Journal of Quality \& Reliability Management, 24(3), 244-262.

Leong, L. Y., Jaafar, N. I., \& Ainin, S. (2018). Understanding Facebook Commerce (F-Commerce) actual purchase from an Artificial Neural Network perspective. Journal of Electronic Commerce Research, 19(1).

Lewis, B. R. \& Soureli, M. (2006). The antecedents of consumer loyalty in retail banking. Journal of Consumer Behaviour, 5(1), 15-31.

Liébana-Cabanillas, F., Herrera, L. J., \& Guillén, A. (2016). Variable selection for payment in social networks: Introducing the Hy-index. Computers in Human Behavior, 56, 45-55. 
Liébana-Cabanillas, F., Higueras-Castillo, E., Molinillo, S., \& Montañez, M. R. (2019b). Assesing the role of risk and trust in consumers' adoption of online payment systems. International Journal of Information Systems and Software Engineering for Big Companies (IJISEBC), 5(2), 99-113.

Liébana-Cabanillas, F., Marinković, V., \& Kalinić, Z. (2017). A SEM-neural network approach for predicting antecedents of m-commerce acceptance. International Journal of Information Management, 37(2), 14-24.

Liébana-Cabanillas, F., Marinkovic, V., de Luna, I. R., \& Kalinic, Z. (2018). Predicting the determinants of mobile payment acceptance: A hybrid SEM-neural network approach. Technological Forecasting and Social Change, 129, 117-130.

Liébana-Cabanillas, F., Marinkovic, V., de Luna, I. R., \& Kalinic, Z. (2018). Predicting the determinants of mobile payment acceptance: A hybrid SEM-neural network approach. Technological Forecasting and Social Change, 129, 117-130.

Liébana-Cabanillas, F., Molinillo, S., \& Ruiz-Montañez, M. (2019a). To use or not to use, that is the question: Analysis of the determining factors for using NFC mobile payment systems in public transportation. Technological Forecasting and Social Change, 139, 266-276.

Liébana-Cabanillas, F., Sánchez-Fernández, J. \& Muñoz-Leiva, F. (2014a). Antecedents of the adoption of the new mobile payment systems: The moderating effect of age. Computers in Human Behavior, 35, 464-478

Liébana-Cabanillas, F., Sánchez-Fernández, J. \& Muñoz-Leiva, F. (2014c). Role of gender on acceptance of mobile payment. Industrial Management \& Data Systems, 114(2), 220-240.

Liébana-Cabanillas, F., Sánchez-Fernández, J., \& Muñoz-Leiva, F. (2014b). The moderating effect of experience in the adoption of mobile payment tools in Virtual Social Networks: The m-Payment Acceptance Model in Virtual Social Networks (MPAM-VSN). International Journal of Information Management, 34(2), 151-166.

Lillington, K., (1999, July 27 $7^{\text {th }}$. Paypal puts dough in your palm. Wired. Retrieved from: https://www.wired.com/1999/07/paypal-puts-dough-in-your-palm/. Last accessed: Feb 1st, 2018.

Lu, J., Wei, J., Yu, C. S., \& Liu, C. (2017). How do post-usage factors and espoused cultural values impact mobile payment continuation?. Behaviour \& Information Technology, 36(2), 140-164.

Ma, L., Zhao, X., Zhou, Z., \& Liu, Y. (2018). A New Aspect on P2P Online Lending Default Prediction using Meta-level Phone Usage Data in China. Decision Support Systems. IN press.

McMillan, J. (2015). The end of banking: money, credit, and the digital revolution. BookBaby

Mercator Advisory Group (2015). European Mobile Person-to-Person Payment Systems: A Changing Environment. Available in https://www.mercatoradvisorygroup.com/Notes/European_Mobile Person-toPerson Payment Systems A Changing Environment/ Last accessed: Feb 1 ${ }^{\text {st }}, 2018$

Mossberger, K., Tolbert, C. J. \& McNeal, R. S. (2007). Digital citizenship: The Internet, society, and participation. MIT Press. 
Neal, R. M. (1996). Bayesian learning for neural networks. New York: Springer.

Neves, J.C, Vieira, A. (2006). Improving bankruptcy prediction with hidden layer learning vector quantization. European Accounting Review, 15(2), 253-271.

Nysveen, H., Pedersen, P. E. \& Thorbjørnsen, H. (2005). Intentions to use mobile services: Antecedents and cross-service comparisons. Journal of the Academy Of Marketing Science, 33(3), 330.

Parasuraman, A., Zeithaml, V. A. \& Berry, L. L. (1988). Servqual: A multiple-item scale for measuring consumer perc. Journal of Retailing, 64(1), 12.

Pavlou, P. A. (2002). Institution-based trust in interorganizational exchange relationships: the role of online B2B marketplaces on trust formation. The Journal of Strategic Information Systems, 11(3-4), 215-243.

PMNTS.com (2015, July 2nd). Throwback Thursday: PayPal's biggest days in history. Retrieved from: http://www.pymnts.com/in-depth/2015/throwback-thursday-paypals-biggest-days-in-history/. Last accessed: Feb 1", 2018.

Ramos-de-Luna, I., Liébana-Cabanillas, F., Sánchez-Fernández, J., \& Muñoz-Leiva, F. (2019). Mobile payment is not all the same: The adoption of mobile payment systems depending on the technology applied. Technological Forecasting and Social Change, 146, 931-944.

Ramos-de-Luna, I., Montoro-Ríos, F. \& Liébana-Cabanillas, F. (2016). Determinants of the intention to use NFC technology as a payment system: an acceptance model approach. Information Systems and e-Business Management, 14(2), 293314.

Renaud, K., \& Van Biljon, J. (2008). Predicting technology acceptance and adoption by the elderly: a qualitative study. In Proceedings of the 2008 Annual Research Conference of the South African Institute of Computer Scientists and Information Technologists on IT Research in Developing Countries: Riding the Wave of Technology (pp. 210-219). SAICSIT '08, Vol 338. New York: ACM.

Řezáč M, Řezáč F (2011). How to measure the quality of credit scoring models. Czech Journal of Economics and Finance, 61(5), 486-507.

Richtel, M. (2002, July $\left.9^{\text {th }}\right)$. EBay to buy PayPal, a rival in online payments. Retrieved from: http://www.nytimes.com/2002/07/09/business/ebay-to-buy-paypal-a-rival-in-online-payments.html. Last accessed: Feb $1^{\text {st }}, 2018$

Rouibah, K., Lowry, P. B. \& Hwang, Y. (2016). The effects of perceived enjoyment and perceived risks on trust formation and intentions to use online payment systems: New perspectives from an Arab country. Electronic Commerce Research and Applications, 19, 33-43.

Sanchez-Franco, M. J., Ramos, A. F. V. \& Velicia, F. A. M. (2009). The moderating effect of gender on relationship quality and loyalty toward Internet service providers. Information \& Management, 46(3), 196-202. 
Shaikh, A. A. \& Karjaluoto, H. (2015). Mobile banking adoption: A literature review. Telematics and Informatics, 32(1), 129142.

Sharma, S. K., Sharma, H., \& Dwivedi, Y. K. (2019). A Hybrid SEM-Neural Network Model for Predicting Determinants of Mobile Payment Services. Information Systems Management, 1-19.

Singh, J. \& Sirdeshmukh, D. (2000). Agency and trust mechanisms in consumer satisfaction and loyalty judgments. Journal of the Academy of Marketing Science, 28(1), 150-167.

Singh, N., Sinha, N., \& Liébana-Cabanillas, F. J. (2020). Determining factors in the adoption and recommendation of mobile wallet services in India: Analysis of the effect of innovativeness, stress to use and social influence. International Journal of Information Management, 50, 191-205.

Susskind, A. M. (2004). Electronic commerce and World Wide Web apprehensiveness: An examination of consumers' perceptions of the World Wide Web. Journal of Computer-Mediated Communication, 9(3), JCMC931.

Swaminathan, V., Lepkowska-White, E. \& Rao, B. P. (1999). Browsers or buyers in cyberspace? An investigation of factors influencing electronic exchange. Journal of Computer-Mediated Communication, 5(2), JCMC523.

Tang, Z. \& Fishwick, P.A. (1993). Feedforward neural nets as models for time series forecasting. ORSA Journal on Computing, 5(4), 374-385.

Taylor, S. \& Todd, P. A. (1995). Understanding information technology usage: A test of competing models. Information Systems Research, 6(2), 144-176.

UPGlobal (2013). The startup revolution, why it matters to corporations. TechStars. Retrieved from: http://www.techstars.com

Vellido, A., Lisboa, P.J.G. \& Vaughan, J. (1999). Neural network in business: a survey of applications (1992-1998). Expert Systems with Applications, 17(1), 51-70.

Venkatesh, V. \& Bala, H. (2008). Technology acceptance model 3 and a research agenda on interventions. Decision Sciences, 39(2), 273-315.

Venkatesh, V. \& Morris, M. G. (2000). Why don't men ever stop to ask for directions? Gender, social influence, and their role in technology acceptance and usage behavior. MIS Quarterly, 115-139.

Venkatesh, V., \& Bala, H. (2008). Technology acceptance model 3 and a research agenda on interventions. Decision sciences, 39(2), 273-315.

Venkatesh, V., \& Davis, F. D. (2000). A theoretical extension of the technology acceptance model: Four longitudinal field studies. Management science, 46(2), 186-204.

Venkatesh, V., Morris, M. G., Davis, G. B., \& Davis, F. D. (2003). User acceptance of information technology: Toward a unified view. MIS quarterly, 425-478. 
Venkatesh, V., Thong, J. Y., \& Xu, X. (2012). Consumer acceptance and use of information technology: extending the unified theory of acceptance and use of technology. MIS quarterly, 157-178.

Wakefield, R. L. \& Whitten, D. (2007). Examining user perception of third-party organization credibility and trust in an eretailer. End user computing challenges and technologies: emerging tools and applications: emerging tools and applications, 1-19.

West, D. (2000). Neural network credit scoring models. Computers and Operations Research, 27(11-12), 1131-1152.

Wilska, T. A. (2003). Mobile phone use as part of young people's consumption styles. Journal of consumer policy, 26(4), 441463.

Wilson N, Altanlar A (2014): Company Failure Prediction with Limited Information: Newly Incorporated Companies. Journal of the Operational Research Society, 65, 252-264

Wong, F.S. (1991). Time series forecasting using backpropagation neural networks. Neurocomputing, 2, $147-159$.

Wu, J., Liu, L., \& Huang, L. (2017). Consumer acceptance of mobile payment across time: Antecedents and moderating role of diffusion stages. Industrial Management \& Data Systems, 117(8), 1761-1776.

Xu J. (2014) B2C Digital Enterprise: E-Tailing. In: Managing Digital Enterprise. Atlantis Press, Paris

Zhang, G.P., Patuwo, B. E. \& Hu, M. Y. (1998). Forecasting with artificial neural networks: The state of the art. International Journal of Forecasting, 14, 35-62.

Zhou, L., Dai, L. \& Zhang, D. (2007). Online shopping acceptance model-A critical survey of consumer factors in online shopping. Journal of Electronic commerce research, 8(1), 41.

Zhou, T. (2013a). Understanding the effect of flow on user adoption of mobile games. Personal and ubiquitous computing, 17(4), 741-748.

Zhou, T. (2013b). An empirical examination of continuance intention of mobile payment services. Decision Support Systems, 54(2), 1085-1091. 


\section{Appendix 1: Constructs and measurement ítems}

\section{Perceived Ease of Use (Venkatesh and Bala, 2008) *}

Interaction with the system does not require great effort (PEOU1)

Interaction with the system is straightforward

It's easy to get the system to do what I want (PEOU3)

The system is useful for making small payments (PEOU4)

In general, the system is easy to use (PEOU5)

Perceived risk of peer-to-peer mobile payment system (Jarvenpaa et al., 2000; Wakefield and Whitten, 2007) *

Other people can get information about my online transactions if I use this tool (PR1)

There is a high potential for money wasted if I make purchases on the internet/social networks using this tool (PR2)

There is significant risk in making purchases on the internet/social networks using this tool (PR3)

I think that making purchases on the internet/social networks with this tool is a risky choice (PR4)

Perceived usefulness of peer-to-peer mobile payment systems (Bhattacherjee and Premkumar, 2004)*

Peer-to-peer mobile payment systems are useful payment methods (PU1)

Using peer-to-peer mobile payment systems makes it easier to handle payments (PU2)

Peer-to-peer mobile payment systems allow quick use of mobile applications (PU3)

In general, peer-to-peer mobile payment systems could be useful for me (PU4)

Perceived trust of peer-to-peer mobile payment system (Pavlou, 2002) *

I believe the peer-to-peer mobile payment system will keep its promises and commitments (TR1)

The peer-to-peer mobile payment system is trustworthy(TR2)

I would describe peer-to-peer mobile payment system as honest (TR3)

I believe the peer-to-peer mobile payment system is responsible (TR4)

In general, I trust the peer-to-peer mobile payment system (TR5)

Personal innovativeness in information technology (Agarwal and Prasad, 1998; Ramos-de-Luna et al., 2016) *

If I find out about new information technology, I seek ways to experience it (PII1) 
Perceived enjoyment of the peer-to-peer mobile payment system (Agarwal and Karahanna, 2000 Rouibah et al., 2016) *

I have fun interacting with this peer-to-peer mobile payment system (PENJ1)

Using this peer-to-peer mobile payment system provides me with a lot of enjoyment (PENJ2)

I enjoy using this peer-to-peer mobile payment system (PENJ3)

Banking brand loyalty (Gözükara and Çolakoğlu, 2016) *

I will not buy other brands if this brand is available at the store (LOY1)

I consider myself loyal to this brand (LOY2)

This brand would be my first choice (LOY3)

I rarely switch from this brand just to try something different (LOY4)

Perceived quality (Parasuraman et al., 1988; Lai et al., 2007) *

When peer-to-peer mobile payment systems promise they will do something, they do (QUAL1)

I consider peer-to-peer mobile payment systems to be dependable (QUAL2)

Peer-to-peer mobile payment systems provide the services they promise when they are supposed to (QUAL3)

Peer-to-peer mobile payment systems accurately maintain the statement (QUAL4)

It is easy to obtain related service information (QUAL5)

It feels safe to do business with the company (QUAL6)

The statement is clear and ease to understand (QUAL7)

Intention to use peer-to-peer mobile payment systems (Venkatesh and Bala, 2008) * 
Given the opportunity, I will use mobile peer-to-peer mobile payment systems (IU1)

I am likely to use peer-to-peer mobile payment systems in the near future (IU2)

I am open to using peer-to-peer mobile payment systems in the near future (IU3) 